\title{
Nachruf auf Herrn Professor Dr. med. Jörg Ritter
}

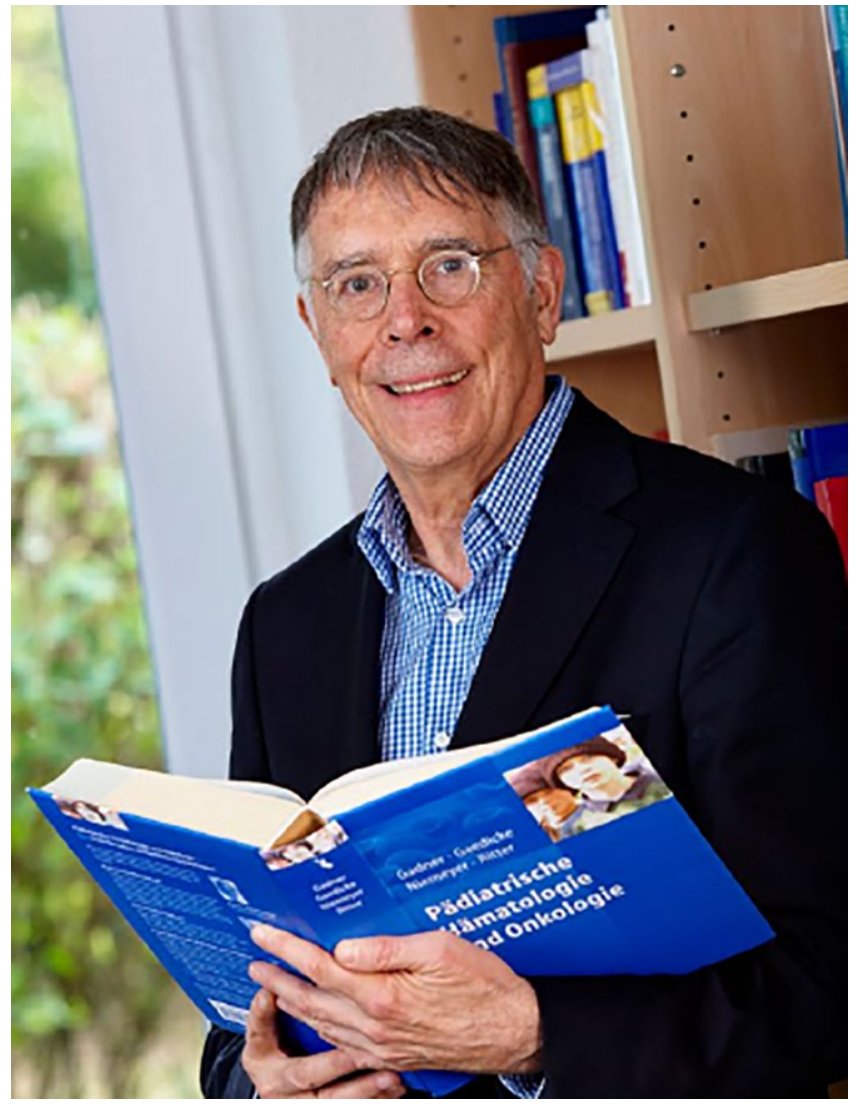

Prof. Dr. Jörg Ritter (@Hinz Photography)

Am 17. Juli 2019 ist nach kurzer Krankheit Herr Professor Dr. med. Jörg Ritter, langjähriger Oberarzt der Klinik für Pädiatrische Hämatologie und Onkologie des Universitätsklinikums Münster und emeritierter ordentlicher Professor der Universität Münster, im Alter von 74 Jahren verstorben.

Prof. Dr. Jörg Ritter studierte Medizin in Wien und Freiburg, wo er auch promovierte. Er begann seine ärztliche Laufbahn an der Medizinischen Hochschule Hannover in den Fächern innere Medizin und Chirurgie, ehe er wieder nach Freiburg in die Kinderklinik wechselte. Von 1972 bis 1973 war er Stipendiat der Deutschen Forschungsgemeinschaft am Max-Planck-Institut für Immunbiologie in Freiburg. Anschließend absolvierte er seine

best practice onkologie 2019 • 14 (12): 582

https://doi.org/10.1007/s11654-019-00191-6

Online publiziert: 14. November 2019

(c) Springer Medizin Verlag GmbH, ein Teil von Springer Nature 2019
Facharztausbildung zum Pädiater, die er 1978 abschloss, in der Universitätskinderklinik Hamburg-Eppendorf und in der Kinderklinik Braunschweig. Im Jahr 1979 wechselte er an die Kinderklinik der Universität Münster, wo er sich 1982 habilitierte.

Prof. Ritter war an wesentlichen Entwicklungen in der pädiatrischen Hämatologie beteiligt, er war Mitglied mehrerer Fachgesellschaften und Autor zahlreicher wissenschaftlicher Publikationen sowie Mitherausgeber des deutschsprachigen Standardwerks: Pädiatrische Hämatologie und Onkologie.

Für sein Engagement wurde Prof. Ritter mit mehreren wissenschaftlichen Preisen ausgezeichnet, u. a. mit dem Kind-PhilippPreis für Leukämieforschung des Stifterverbands der Deutschen Wissenschaft, den er zusammen mit Professor Schellong und Frau Professor Creutzig für die Etablierung und Durchführung der pädiatrischen Studien zur akuten myeloischen Leukämie (AML) erhielt.

Im Oktober 2010 wurde Prof. Ritter von der Westfälischen Wilhelms-Universität zum Senior Professor ernannt und war bis zuletzt ordentliches Mitglied der Ethik-Kommission der Ärztekammer Westfalen-Lippe und der Westfälischen Wilhelms-Universität Münster. Seine Leidenschaft waren die Musik und seine Viola: Neben dem Musizieren im kleinen kammermusikalischen Kreis war er seit 1971 aktives Mitglied des Deutschen Kinderärzteorchesters und als Senior Professor Organisator und Moderator der Vortragsreihe „Medizin und Musik“ der Medizinischen Fakultät.

Prof. Ritter war seit $2007 \mathrm{im}$ wissenschaftlichen Beirat von best practice onkologie tätig. Wir haben ihn als extrem interessierten und engagierten Menschen erlebt, der sich sehr für die Belange der Zeitschrift eingesetzt hat. Zuletzt war Prof. Ritter als Herausgeber für die Sektion „Pädiatrische Onkologie“ aktiv.

Wir verlieren in Prof. Ritter einen geschätzten Kollegen, der aktiv zu Gestaltung unserer Zeitschrift beigetragen hat.

Prof. Dr. S. Schmitz

Schriftleiter

Im Namen aller Herausgeber der Zeitschrift best practice onkologie

\section{Korrespondenzadresse}

\section{Prof. Dr. S. Schmitz}

MVZ für Hämatologie und Onkologie Köln Sachsenring 69, 50677 Köln, Deutschland schmitz@onkokoeln.de 